\title{
On the Historical Value of Wang Juzheng 's "Spinning Wheel Drawing" in the Northern Song Dynasty
}

\author{
Shaoduan Zhang \\ Luoyang Normal University \\ Luoyang, China
}

\begin{abstract}
Genre painting is an important category of Song Dynasty painting. The genre painting in Song Dynasty broke through the frame which take religious and upper aristocratic life as the main content, and began to focus on the real life of common people in art works. These genre paintings took urban and rural ordinary people and their living environment as performance object, the expression method is meticulous and vivid, reflecting the superb level of Song Dynasty painting art. Wang Juzheng's "Spinning wheel drawing" in Northern Song Dynasty is one of the representative works of genre painting in this period. The analysis of this work has great value in studying the social structure and the style of painting in Northern Song Dynasty.
\end{abstract}

Keywords-Northern Song Dynasty; genre painting; Wang Juzheng; "Spinning Wheel Drawing"

\section{INTRODUCTION}

As one of the categories of Chinese figure painting, genre painting has an extremely important position and influence in the history of Chinese art. Genre painting is a unique form of national painting, with the artistic characteristics of simple and natural style, cordial and moving content, vivid and vibrant image, rich flavor of life and so on. It is like a mirror, reflecting the national, geographical and local customs and life. This form of painting originally produced from the soil of folk art and close to the public's spiritual life and aesthetic needs. In China's primitive society, human natural life scenes are expressed in the original paintings so that is the start of Chinese genre painting. But in the literal sense genre painting began in the Five Dynasties, popular in the Song Dynasty. In the early and middle of Northern Song Dynasty, due to the prosperity of the city economy there have been some outstanding works of genre painting. Wang Juzheng's "Spinning Wheel Drawing" is one of the representative works of this period "Fig. 1", the analysis of this work has great value in studying the social structure and the style of painting in the Northern Song Dynasty.

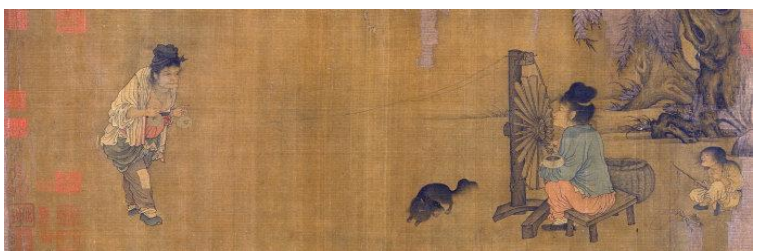

Fig. 1. "Spinning Wheel Drawing"

\section{THE SOCIAL CONDITION OF NORTHERN SONG DYNASTY}

The establishment of Northern Song Dynasty ended the country split situation since the end of Tang Dynasty, and formed the coexistence of Song, Liao and Xixia. After more than ten years of wars, Song Taizu Zhao Kuangyin destroyed the resistance of local forces of Late Zhou Dynasty, conquered Jingnan, Late Shu, Southern Han, Southern Tang and other local regimes. After Song Taizong ascended the throne, he destroyed North Han, so since An Shi Rebellion, two hundred years of feudal warlord separatist situation was basically over.

In the early days of Northern Song Dynasty, the rulers focused on reforming the political, military and economic systems to ensure the government of Song Dynasty will have a long period of stability. To the middle of Northern Song Dynasty, the development of social productive forces reached an unprecedented level, feudal production relation has also undergone major changes and adjustments. The city's function has undergone an important transformation, gradually changed from political and military as the center to the commercial and culture as the center. During this period, agriculture, textile industry, porcelain industry, paper industry, printing industry, business and so all have a rapid development opportunity. A large number of cities rose, so that the number of citizens exceed all the previous era, at that time the population in the capital Bianliang was more than one million. "Dong Jing Meng Hua $\mathrm{Lu}^{\prime}$ recorded the business prosperity of Bianjing City: Big streets and small alleys, shops everywhere, all the bars and show places, extremely lively, royal porches on both side of the royal street allow businessmen set up trading stalls, to the south of Royal Street until Zhuque Gate, there are hotels, restaurants, pharmacies, tea-houses, shops, night market until three o'clock at night. On the east is East street, there are fish market, meat market, gold and silver lacquer shop; West Street has jade and jewelry shops and fresh fruit shops. Outside the city of the southeast direction there is Crossing street where shops and merchants gathered, majestic house with wide front door, each transaction easily exceed tens of millions, and also there are more than fifty different sizes of show places and bars there, among which lotus shed and peony shed could accommodate thousands of viewers, besides plays and operas, there are also tea selling, painting selling, divination, gambling and other activities. Due to the development of industry and commerce and the prosperity of city economy, the number of handicraft 
workers and citizens continue to expand, the folk, popular culture and entertainments which contrast with the elegant culture of the landlord upper class have been a great development. The unprecedented growth of urban cultural life has also led to a significant increase in the demand for painting. The serve object of painting has also been expanded which provide material conditions and mass basis for the development and prosperity of painting. To the late Northern Song Dynasty, social contradictions are becoming increasingly serious. The number of troops soared, so that the national financial deficit year after year, land annexation intensified, there is the situation of poor and weak. This period is the most decadent and the darkest stage, domestic trouble and foreign invasions came together. In order to maintain royal family's extravagant life and officials' generous salary, royal officials do everything possible to extract the money from people, coupled with land annexation and brutal land rent exploitation, forcing people had to uprising. In this context, literature and painting works at that time often reflect the content of class contradictions and sympathy for people's suffering.

\section{OVERVIEW OF WANG JUZHENG AND HIS "SPINNING WHEEL DRAWING"}

Wang Juzheng, from Hedong (now Yongji, Shanxi), the son of Wang Zhuo, famous painter of Northern Song Dynasty, who was often called Hange, lived in Song Renzong period (1023-1063 before or after), he learned painting since childhood by his father, his painting has his father's style so he and his father Wang Zhuo together were famous in painting world. He was good at painting ladies, learned from Zhou Fang, he learned his leisure state. He often stood on the spot where visitors toured and observed their mass appearance and beauty's charm, especially nuanced. Before he started, he meditated and thought calmly, and strived to achieve unity of form and spirit, so his works were ingeniously conceived with vivid image and delicate real depict. His works include "Tiao Yingwu Shinv Tu", "Lvchuang Jiaoyu Tu" and so on, handed down work is "Spinning Wheel Drawing" volume.

Wang Juzheng's "Spinning wheel drawing" is one of the representative genre works in Northern Song Dynasty, silk with color, vertical $26.2 \mathrm{~cm}$, horizontal $69.2 \mathrm{~cm}$, no author's seal. It was collected by Zhao Mengfu so it has Zhao Mengfu's second postscript, which said, "although the drawing is only foot long, but pen rhyme is magnificent, it has high-life meaning and wonderful touches, really can be described as God's work." And there is a poem: "rural women make spinning after the farm work, spinning wheel gives out squeak. The kind women are diligent in spinning, but they do not envy the silk. Child is good at play, with a dog squatting quietly...." Now the second postscript no longer exists, only the postscripts of Yuan Tingyu, Wu Kuan from Ming and Qing Dynasty are left, now collected in the National Palace Museum.

\section{THE SOCIOLOGICAL AND HistoricAl VALUE OF "SPINNING WHEEL DRAWING"}

"Spinning wheel drawing" depicts the rural women's textile scene. The picture is very simple, on left side there is an old woman with thread on both hands; on right side there is a middle-aged peasant woman hold a baby, shake the spinning wheel on one hand; behind her there is a child sitting on the ground holding a small pole, tied a frog for game; In front of her there is a puppy playing. Scene setting is simple, the upper right corner painted two pieces of old trees trunk, a few strings of willow hanging, a ridge and a little bit grass. There are no extra props in the drawing to express figure's activity, only spinning wheel, bamboo basket and wooden stool, puppy and frog are also an indispensable thing to convey the taste. These show the author's creative ideas are all around the word "Jian", strive to achieve refine, typical, general, without pretender, one can be used as ten. And those coarse clothes, monotonous clothes make people feel that this is a relatively poor lower class people and ordinary family. Old woman's pants with patches on both knees and middle-aged peasant's clothes with patch on the shoulder are very eye-catching, which directly pointed out the social phenomenon which farmers and weavers can not get enough clothes and food, those who spend all year spinning and weaving couldn't get good clothes. Under the reflection of above described aspects, the characters look particularly vivid. Old woman and middle-aged peasant woman, child are the member of an ordinary family, men has been to work, women bear the heavy responsibility of the housework, but also express the thrifty nature, the author through his realistic way to talk about his understanding of life, show his deep sympathy for the lower class people. Old woman dry thin face engraved with bitter wrinkles, deep eye socket with glassy eyes, bent over, bow back, shriveled hands holding two lines very hard, tired to support the weight of life. Daughter-in-law looking at her mother-in-law, there is a lot of mercy in her eyes, she must keep shaking the wheel, but also need to feed the baby, from her sitting position, she obviously has a backache leg already. Only the child does not worry, it played with the tied frog while looking at the spinning wheel. Faced with such a vivid small scene and carefully taste it, won't it content with multi-layer meaning of life?

The early and middle period of Northern Song Dynasty, due to the development of urban commercial economy and the growth of common citizen class, it had a profound impact on painting art. Painting was not only minority's elegant entertainment and collection, it began to become a commodity into the market, thus forming the painting market already took shape. With the commercialization of painting and the formation of painting market, it provided possibilities for the free creation of painters. At the same time, due to the rapid development of handicraft industry and business, petty bourgeoisie, represented by the citizens has become the new consuming class for calligraphy and painting, which pushed painting theme changed from Buddhism and Aristocratic into genre paintings which depict the real life of "little citizen". These genre paintings broke through the limitation of the past figure paintings which mainly themed by emperors, saints and concubines, and got rid of the traditions of figure painting which was "learn from the saints and alert from the fools". Its subject matter is quite extensive, all aspects of public life are involved, such as the street vendor, children play game, lady, horse, street market, city, farming and weaving, cars, as well as village pasture, village doctor, village school, food transport and so on. Most of the painters who create these genre paintings were living in the masses and were very familiar with their life and mental state, and carried out vivid and concrete depiction on the basis of in-depth observation, reflecting the 
spiritual demands and aesthetic demands of a considerable number of people in the community, which will push the development of Song Dynasty genre painting to a climax.

The emergence of the themes which reflect the development of the city's economy and common people's life, is the phenomenon worth noting in Song Dynasty painting development. There were many painters who are good at paintings life scenes at that time. The painters use their excellent artistic observation, their excellent organization and arrangement ability for complex scenes and mass characters, as well as their in-depth and detailed description skills of the details to reproduce the daily life scene which ordinary people turn a blind eye on the painting, so that people often have immersive and familiar intimacy. The "Riverside Scene at Qingming Festival" painted by Zhang Zeduan in Northern Song Dynasty and "Spinning wheel drawing "painted by Wang Juzheng are the most representative works. The whole picture of "Riverside Scene at Qingming Festival" shows the city's bustling atmosphere, including all aspects of urban life, all the industries and people from all social class both men and women, everything was in it. But "Riverside Scene at Qingming Festival" shows more of the bustling city life in the capital of Northern Song Dynasty, pay attention to rendering the overall atmosphere of the city; But "Spinning wheel drawing" concerned more about the real life of countryside, use the local detail of "knowing the cool autumn from a falling leaf" to analyze and reproduced the real scene of feudal society brutally exploit common people, on one hand expressed of the old woman 's overwhelmed feeling, but also the perfectly expressed painter's sympathy for laboring people. Therefore, Wang Juzheng's "Spinning wheel drawing" reflect ordinary people's living conditions who suffered at the bottom of Northern Song Dynasty's society from another point of view, it has important historical value for study the social form and structure in the historical period.

\section{The ARtistic FeAtures And ARt History VAlue of "SPINNING WHEEL DRAWING"}

Song Dynasty's genre painting with its wide range themes which close to life, vividly reproduced the social life of Song Dynasty. And the majority of the public class has become the consumer of these genre paintings, so these genre paintings all have a high realism in order to meet their aesthetic demands. At the same time the plot and interest of the paintings also are important factors to attract them.

Wang Juzheng's "Spinning Wheel Drawing" has a strong realism, the painter depicted very detailed and very real characters in the picture, also he depicted small animal's manner lifelike. Spinning wheel and bamboo stool are also meticulously highlighted its texture. At the same time, "Spinning wheel drawing" play the "live interesting" this feature most vividly, although the painter expressed the hard labor life of the mother-in-law and daughter-in-law, but he did not forget to use the child who play toad and lively puppy to break the boring picture. The layout and means of the whole painting is very clever and interesting. Painter left the center place to the two wretched thin lines, those thin lines brought out all the figures, first is the hard work old woman and middle-aged peasant woman. While the painter represent this theme, he introduced another plot as well, which inject a lively atmosphere to this quiet scene, contrast the life scene more vivid, more realistic and more real. That is, the painter draws the child behind the peasant woman, he sat on the floor, hold a wooden pole on one hand with a toad, seems to wait for the baby in peasant woman's arms to play with him, also it seems to listen to the puppy barking. "Live interesting" feature can be seen from here.

"Spinning Wheel Drawing" is a masterpiece with realism, it fully demonstrated the painter Wang Juzheng's unique understanding and experience of life, which can be confirmed by comparing with the previous paintings works. In Tang Dynasty also has the painting about labor scenes, such as Zhang Xuan's "Daolian Tu", the women in painting engaged in silk fiddle, maintenance, sewing and other activities, the subject depicts the scene of labor production, but the figures wearing fancy clothes with "full and round body", so it reflects the aristocratic women's life But the women in Wang Juzheng's works have haggard face and skinny body, drowsy and dressed ragged, it shows the poor farmers image who can not get enough food and clothing all the time. He focus on the lower class people, through the elaborate and in-depth image depiction of the workers reflect the real life with art forms in order to recall the audience and society's sympathy and concern. It provided an important historical value for the descendants' study of society, culture, history and farmers' living conditions at that time.

The two women images in "Spinning Wheel Drawing" break the limits of traditional themes, especially feudal ethical code. In ancient China, because the rituals bound of "male and female unaccompanied", nude image can not appear in the traditional Chinese painting which "enlightenment and educate people". This is obvious in the ancient painting works, such as the Eastern Jin Gukai's "Lienv Renzhi Tu", "Nvshi Jiantu" and other works have a political and religious role, when they express female images, mostly they will process and hide the breast structure which shows female beauty characteristics. When Wang Juzheng expresses these two female images in "Spinning wheel drawing", the old woman "expose her breasts", middle-aged peasant also feed her baby in her sideways with her breast exposed. "Spinning wheel drawing" painted people's exposed body so realistic and in detail, it is a bold breakthrough in art, but also a directly challenge to the social system and imprisonment of human justice at that time, so it has unusual significance.

The painting style of "Spinning Wheel Drawing" also has the meaning of inherit the past and usher in the future. Its painter was ingenuity in the composition, full of new ideas. Two-thirds of the background of the picture is empty, all the scene compressed in the corner, the main body of the figures' activity also focus on one place, so that the right one-third part of the picture full with changes, with complex content and obvious layers, with both scene and figure, both situation and environment. The two willows in the upper left corner of the picture are not only has accurate proportion and perspective relationship with the front figures, but also reflect the unique meaning of it as a background, which implies the location of the figures in the painting, and the previous figure paintings either with no background, or the landscape and the trees are 
only appeared as a small background for the figure painting. And the old women was at the left side of the painting who pressed the composition "position", two fluttering slim cotton thread connect left and right side to create a balanced, complete trend, not dull, this can be described as the finishing point. Look at both ends of the full picture, one side shows "airtight" trend, while other end shows "wide open" situation, it create obvious contrast and ups and downs rhythm which pleased the audience. In the color setting of "Spinning wheel drawing", Wang Juzheng greatly changed Tang Dynasty's bright color style, but chose dark colors to fit the lower people' images, the whole color setting has a sense of rhythm. In the pencraft, he did not choose the smooth, free and easy line forms like "Cao Yi Chu Shui" or "Wu Dai Dang Feng", but he chose involved and abstruse pencraft to draw the image, figure's close pattern he use sharp turning "Zhan bi miao" to express, draw with the middle part of the pen with thin and round lines, along with the figure's body change he makes stops and turns, so as to accurately shape figure's from and the texture of clothing, so that to make people feel the overwhelmed feelings which the figures bear.

"Spinning wheel drawing" in painting performance not only different from Su Hanchen's concentrated aristocratic style, but also different from Yan Ciping's light simple literati style, but he felt the sorrow and happy of theirs, and share happiness and sufferings with the working people which has the special meaning to make a history.

\section{CONCLUSION}

Song Dynasty genre painting occupies an important position in the history of Chinese painting, the association with the social reality at that time and the literature meaning it content all worthy of our discussion. And as one of the representative works of this period, "Spinning wheel drawing" fully demonstrated the people's overwhelmed feelings for the life, profoundly expressed author's sympathy for the mentality of people, showing its unique culture vitality and artistic function, it should get people's attention and protection.

\section{REFERENCES}

[1] Zhang Shuheng, Li Tao. Chinese painting art appreciation. Hohhot: distant press, 2006.1

[2] Wang Zhiyan, Li Gong. China Charm Series. Beijing: Yanshan Publishing Company, 2006.11

[3] Tang Jian. Chinese art history painting. Tianjin: Tianjin People's Fine Arts Publishing Company, 2001.12

[4] Zou Manxing. Journal of Xi'an University of Arts and Science. Jinan: Shandong Fine Arts Publishing Company, 2006.6

[5] Zhang Shuheng. Chinese famous painting fast pic. Hohhot: distant press, 2004.8

[6] Zhou Feng. Dongyue Luncong. Jinan, 2002.5 P68

[7] Wu Liefu, Shao Luoyang. Chinese painting appreciation dictionary. Shanghai: Shanghai Lexicographical Publishing Company, 2006.12 